\title{
COMUNICACCÕES
}

\section{Mancha-alvo em pepino japonês sob hidroponia no Pará}

\author{
Tathianne Pastana de Sousa Poltronieri ${ }^{1}$; Luiz Sebastião Poltronieri²; Jaqueline Rosemeire Verzignassi³ ${ }^{3}$ Ruth Linda \\ Benchimol$^{2}$; Eudes de Arruda Carvalho ${ }^{2}$
}

\begin{abstract}
${ }^{1}$ Departamento de Fitopatologia e Entomologia, Instituto de Biologia, Universidade Federal Rural do Rio de Janeiro, CEP 23890-000, Rio de Janeiro, RJ. ${ }^{2}$ Embrapa Amazônia Oriental, Tv. Enéas Pinheiro, S/N, CEP 66095-100, Belém, PA.; ${ }^{3}$ Embrapa Gado de Corte, Rodovia BR 262, km 4, CEP 79002-970, Campo Grande, MS.

Autor para correspondência: Jaqueline Rosemeire Verzignassi (jaqueline@cnpgc.embrapa.br)

Data de chegada: 09/11/2011. Aceito para publicação em: 19/04/2012 .
\end{abstract}

No estado do Pará, o cultivo hidropônico vem sendo intensificado nos últimos anos, com destaque para as culturas da alface (Lactuca sativa L.), tomate (Lycopersicon lycopersicum L.), pepino (Cucumis sativus L.), jambu (Acmella oleracea L.) e do pimentão (Capsicum annuum $L$ ). Em visitas técnicas efetuadas em áreas de cultivos hidropônicos de pepino japonês no município de Benevides (PA), constatou-se nas folhas de pepino pequenas manchas foliares angulares com o centro marrom claro e bordas encharcadas, de coloração olivácea que, em estádio avançado, coalesciam, provocando o seu secamento e queda. Do material coletado, efetuou-se isolamento em meio de cultura BDA (Batata-Dextrose-Ágar) obtendo-se colônias fúngicas de coloração acinzentada, com micélio aéreo de aspecto aveludado e cotonoso. Os conídios apresentaram forma cilíndrica com base truncada, possuindo de dois a dez septos e medindo de 13 a $83 \mu \mathrm{m}$ de comprimento e 6 a $11 \mu \mathrm{m}$ de largura, características correspondentes

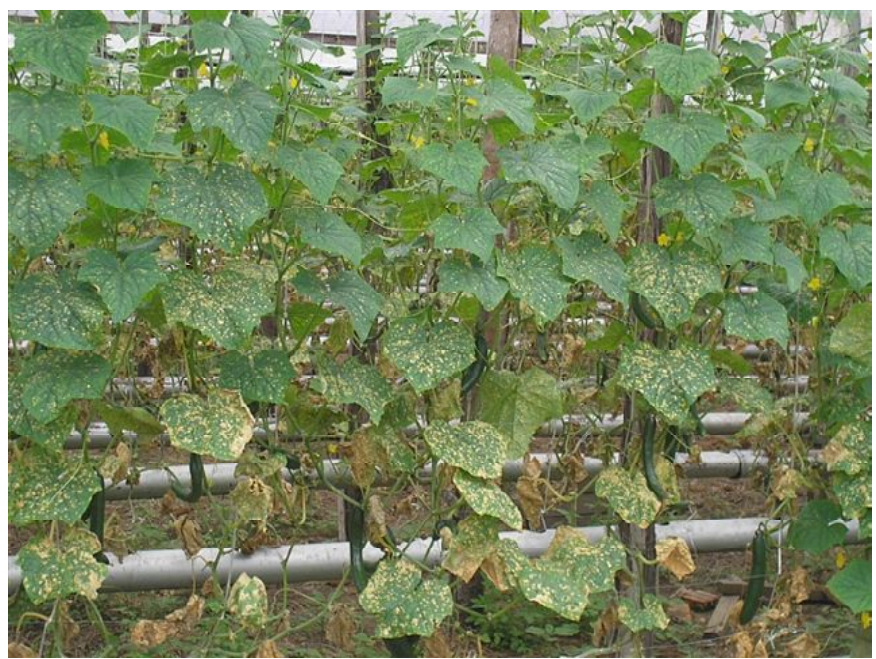

ao fungo Corynespora cassiicola (Berk \& Curt.) Wei. As folhas de pepino sadias foram inoculadas com o fungo, produzindo sintomas semelhantes aos encontrados nas estufas e o reisolamento do patógeno foi realizado, comprovando-se a patogenicidade do fungo. A manchaalvo, causada pelo fungo Corynespora cassicola, pode ocasionar perdas de até $60 \%$ na produção de pepino japonês em plantio comercial sob estufas plásticas, devido à desfolha que provoca nas plantas (Verzignassi et al., Fitopatol. Bras. 28:570, 2003). C. cassiicola foi anteriormente relatado no Pará causando mancha-alvo em juta (Corchorus capsulari L.), cacaueiro (Theobroma cacao L.), tomateiro (Solanum lycopersicum L.), hortência (Hydrangea macrophylla Thumb.), pimenteira longa (Piper hispidinervum C.), aceroleira (Malpighia glabra L.), mamoeiro (Carica papaya L.) e alface (Lactuca sativa L.),. Este é o primeiro relato do fungo em plantas de pepino no sistema de cultivo hidropônico no Pará.

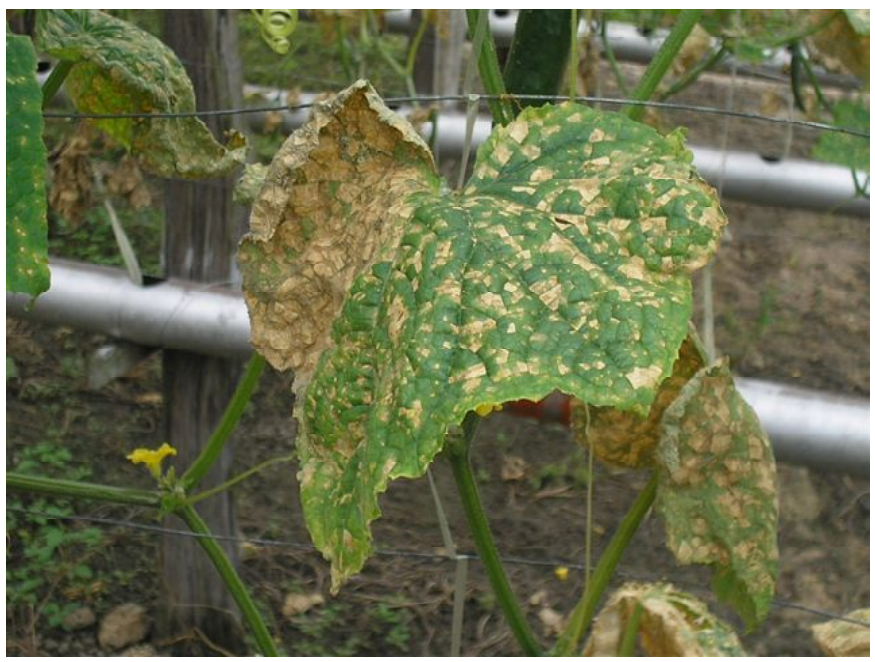

Figura 1. Sintomas de mancha-alvo em pepino japonês sob cultivo hidropônico. 